\title{
Population genetic structure of Banksia spinulosa
}

\author{
SUSAN M. CARTHEW* \\ Department of Biology, University of Wollongong, Wollongong, NSW 2500, Australia
}

\begin{abstract}
This study investigated the genetic structure of a population of the highly outcrossed perennial shrub, Banksia spinulosa. Three variable loci were detected; $P g m_{l}, A d h_{l}$ and $P g i_{2}$. Some genetic differentiation was detected in the population, and as a whole it deviated from a panmictic unit. This primarily resulted from the behaviour of $P g i_{2}$. This locus exhibited a large deficit of heterozygotes, possibly in association with a Wahlund effect. However, deviations from panmixia were small compared with species which are predominantly self-fertilizing, and estimates of gene flow indicated that the movement of genes occurs over a fairly wide area. This study provides the first description of spatial genetic variability within a population of Banksia spinulosa.
\end{abstract}

Keywords: Banksia spinulosa, genetic structure, isozyme analysis, outcrossing, population genetics, Proteaceae.

\section{Introduction}

In plant populations, patterns of mating and population genetic structure are considered to be interrelated. The spatial distribution of genotypes in a population will limit the types of potential mates a plant can have and, in turn, the mating system is generally thought to be an important determinant of the spatial structuring of genes (Loveless \& Hamrick, 1984). For example, panmictic or highly outcrossed populations are usually considered to be relatively homogeneous with genes randomly distributed through the population. On the other hand, inbreeding populations are expected to exhibit genetic structure, existing as small clusters or patches of genetically related individuals (Hamrick et al., 1979). Until recently, however, there have been relatively few studies on microgeographic differentiation of populations for which the mating system is known (Hamrick, 1982), and so these predictions have only rarely been tested for plant populations (but see; Ennos, 1985; Soltis \& Soltis, 1988; Abbott \& Gomes, 1989). Indeed, some of the species studied do not appear to conform to this general view. Spatial structuring of genotypes has been observed in some apparently outcrossing species (Linhart et al., 1981; Silander, 1984; Wendel \& Parks, 1985), while inbreed-

*Correspondence: Department of Environmental Science \& Rangeland Management, University of Adelaide, Roseworthy Campus, Roseworthy, SA 5371, Australia. ing species sometimes show spatial genetic patterns more consistent with panmictic expectations (Brown, 1979). This can arise because the genetic structure of a population will also reflect factors not directly related to the mating system, including evolutionary history, the movement of genes through seed dispersal (e.g. Furnier et al., 1987), genotype-environment interactions (Hedrick, 1985) and natural selection (Mitton et al., 1980). Even in outcrossing species gene flow through pollen and/or seed dispersal is often quite restricted (e.g. Smyth \& Hamrick, 1987). This may then create small neighbourhood sizes and so cause substructuring of populations.

Banksia spinulosa (Family Proteaceae) is a woody perennial shrub which flowers during winter. The main flower visitors are birds, mammals and insects (Carthew, 1993). Flowers are hermaphroditic and are arranged into large compact inflorescences. Individual plants may bear more than 20 inflorescences, allowing geitonogamous pollination. Plants are capable of some self-fertilization, however outcrossed seed is produced preferentially (Carthew, 1991), and rates of outcrossing for open-pollinated seed do not differ significantly from one (Carthew et al., 1988). No information is available on microgeographic differentiation in populations of this species. This study aims to test for genetic structuring of a population of the highly outcrossed $B$. spinulosa, by employing $F$-statistics (Wright, 1978) and assessing population differentiation among five arbitrarily selected subpopulations. 


\section{Methods}

\section{Sampling and electrophoresis}

The study site was located in Barren Grounds Nature Reserve $\left(30^{\circ} 40^{\prime} 30^{\prime \prime} \mathrm{S}, 150^{\circ} 43^{\prime} 15^{\prime \prime} \mathrm{E}\right)$ near Wollongong in NSW, Australia. At this site, B. spinulosa forms the dominant understorey species. All plants in the population were permanently tagged and mapped. Samples of unopened flowers were collected from 302 plants selected at random during the flowering seasons of 1987 and 1988. Sampled plants were scattered throughout the population, and samples from neighbouring plants were sometimes collected (Fig. 1). Flowers were kept refrigerated at $4^{\circ} \mathrm{C}$ until required for electrophoresis. For each sample assayed, pollen from five to 10 unopened flowers was removed and crushed in two drops of borate buffer $(\mathrm{pH} \mathrm{9.0),} \mathrm{which}$ contained soluble polyvinyl pyrrolidone $\left(20 \mathrm{mg} \mathrm{ml}^{-1}\right)$ with small amounts of dithiothreitol $\left(1 \mathrm{mg} \mathrm{ml}^{-1}\right)$ and a pinch of bromophenol blue. Electrophoretic procedures followed the methods outlined in Carthew et al. (1988). Ten polymorphic loci were detected, however only three of these could be resolved consistently.
Fig. 1 Distribution of plants in the study site, showing those plants genotyped at two or three loci (0) and the remainder $(\bullet)$. The boundaries of the five subpopulations are indicated, as is the midpoint of each subpopulation (closed circle surrounded by an open circle).

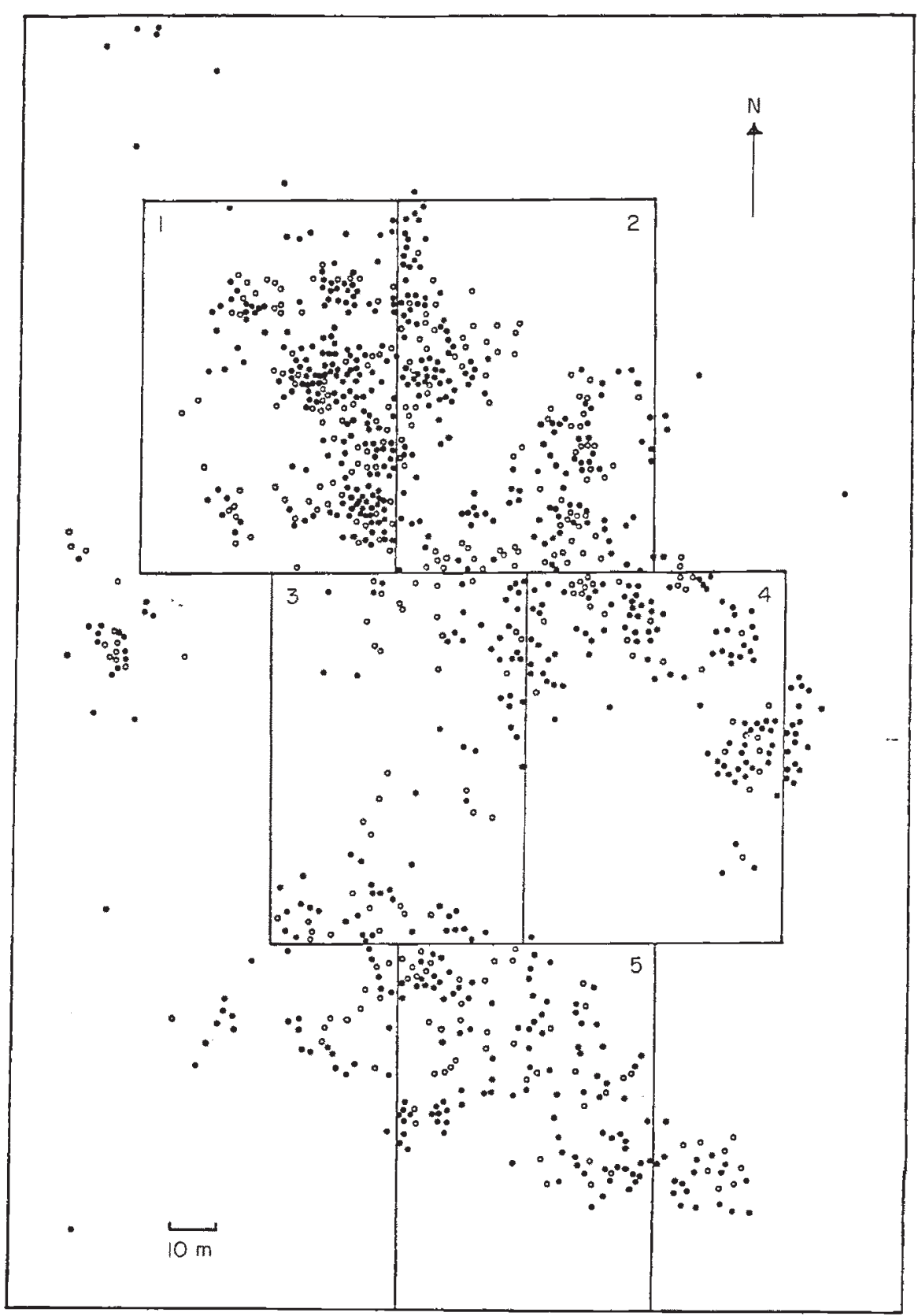


Those samples collected during 1987 were assayed for two enzyme loci; phosphoglucomutase $\left(\mathrm{Pgm}_{l}\right)$ and alcohol dehydrogenase $\left(A d h_{l}\right)$. Those collected in 1988 were scored for an additional locus; glucose-6phosphate isomerase $\left(\mathrm{Pgi}_{2}\right)$. All enzymes were assayed using a Tris-malate buffer system. Descriptions of the enzyme loci for $P g m_{1}$ and $A d h$, can be found in Carthew et al. (1988). For PGI, three areas of activity, attributed to three enzyme loci, were consistently observed in the samples, although only one of these $\left(\mathrm{Pgi}_{2}\right)$ was consistently scorable in pollen. Genetic interpretation of enzyme loci was based on comparisons of pollen genotypes with progeny arrays from open-pollination and controlled crossings (Carthew, 1991). This was possible because pollen and seed material had the same electrophoretic mobility and were therefore considered equivalent. $\mathrm{Pgm_{1 }}$ and $\mathrm{Pgi}_{2}$ conformed to regular Mendelian inheritance for $\mathrm{co}^{-}$ dominant alleles. $A d h_{l}$ appears to contain a null allele. This allele appeared only as a heterozygote with less common alleles, and no homozygote nulls were ever detected, indicating that it is a recessive lethal. As individuals heterozygous for the null allele will appear as homozygotes, slightly fewer heterozygotes will be detected in such individuals.

\section{Data analysis}

Several measures were used to summarize the genetic variability in this population, and for most analyses, calculations were facilitated with the use of the program Blosys-1 (Swofford \& Selander, 1981). To assess intrapopulation variability, the population was subdivided into five arbitrarily defined subpopulations of equal area (Fig. 1). As some sampled plants were outside the defined boundaries (38 individuals), these were excluded from analysis involving the subpopulations but not the total population.

The distribution of genetic variation within and among the subpopulations was analysed using $F$ statistics (Wright, 1978), where $1-F_{\mathrm{IT}}=\left(1-F_{\mathrm{IS}}\right)$ $\left(1-F_{\mathrm{ST}}\right) . F_{\mathrm{IT}}$ is the correlation between individuals within the total sample (i.e. total fixation index), and is made up of two components; $F_{\text {IS }}$, which describes deviations from Hardy-Weinberg expectations within subpopulations, and $F_{\text {ST }}$ which measures differentiation between subpopulations. $F_{\mathrm{ST}}$ was calculated for each allele at each locus, from the relationship $F_{\mathrm{ST}}=\sigma^{2} / p(1-p)$, where $\sigma^{2}$ is the total variance among samples, and $p$ is the mean allelic frequency. As binomial sampling variance can bias values when $F_{\mathrm{ST}}$ is small (Johnson \& Black, 1984), this component was subtracted from estimates of variance (i.e. $\sigma_{\mathrm{c}}^{2}=\sigma^{2}-\sigma_{\mathrm{s}}^{2}$, where $\left.\sigma_{\mathrm{s}}^{2}=p(1-p) / 2 N\right)$, and the corrected variance $\left(\sigma_{\mathrm{c}}^{2}\right)$ was used for calculations of $F_{\mathrm{ST}}$. Heterogeneity of allelic frequencies among subpopulations were calculated for each locus using G-tests. Deviations from Hardy-Weinberg expectations $\left(F_{\text {IS }}\right)$ were tested using heterogeneity chi-square analysis. For $F_{\text {IT }}$, statistical significance was tested using the relationship $\chi^{2}=F_{\mathrm{IT}} 2 N(n-1)$, for $n(n-1) / 2$ d.f., where $n$ is the number of alleles (Ellstrand \& Levin, 1980).

To determine the extent to which any deficits of heterozygotes could be attributed to variance in allelic frequencies among the subpopulations (the Wahlund effect), the relationship between heterozygote deficits and variance of allelic frequencies among subpopulations was calculated as $\Sigma \sigma^{2} / H_{\mathrm{e}}-H_{\mathrm{o}}$ (where $\Sigma \sigma^{2}$ is the variance summed for each locus, $H_{\mathrm{e}}$ is the expected heterozygosity, and $H_{\mathrm{o}}$ is observed heterozygosity for the total population; Johnson \& Black, 1984). In addition, unbiased estimates of Nei's genetic distance, $D$, and genetic identity, $I$ (Nei, 1978) were calculated. Genetic distances were graphed against geographic distances to give a visual representation of their relationship. Geographic distances between populations were calculated from the midpoint of each subpopulation (see Fig. 1).

\section{Results}

Allelic frequencies at each locus for the whole population and each subpopulation are given in Table 1. For $P g m_{l}$ and $A d h_{l}$, four alleles were present, while $P g i_{2}$ had five alleles. The pattern of allele distribution showed some apparent differences among the five subpopulations, with the less common alleles of each locus being absent in certain sections of the population.

Some variation amongst subpopulations and loci were evident for values of $F_{\text {IS }}$, and significant weighted mean values were obtained for $P g m_{l}$ and $A d h_{l}$ (Table 2). In general, $P g m_{l}$ exhibited an excess of heterozygotes, while $\mathrm{Pgi}_{2}$ and $\mathrm{Adh}$, showed deficiencies of heterozygotes. However, when individual subpopulations were considered, statistically significant values were obtained only in subpopulation number 2 for $A d h_{i}$, and subpopulation number 5 for $P g i_{2}$ (Table 2).

Estimates of $F_{\mathrm{ST}}$ for all alleles at each locus are given in Table 3 . With the exception of some of the rarer alleles, which were present in only some parts of the population, these standardized variance values were small for most alleles. Furthermore, only one locus $\left(\mathrm{Pgi}_{2}\right)$ showed significant variation in allelic frequencies among the five subpopulations.

A summary of $F$-statistics for the population, including estimates of the total fixation index $\left(F_{\mathrm{IT}}\right)$ are given in Table 4. Significant deficits of heterozygotes in the population were obtained for $\mathrm{Adh}_{1}$ and $\mathrm{Pgi}_{2}$. Con- 
Table 1 Frequencies of alleles for three loci in pollen samples of $B$. spinulosa from the total sample population and among the five designated subpopulations

\begin{tabular}{|c|c|c|c|c|c|c|c|}
\hline \multirow[b]{2}{*}{ Locus } & \multirow[b]{2}{*}{ Allele } & \multirow[b]{2}{*}{ Total } & \multicolumn{5}{|c|}{ Subpopulation } \\
\hline & & & 1 & 2 & 3 & 4 & 5 \\
\hline \multicolumn{8}{|l|}{$\mathrm{Pgm}_{I}$} \\
\hline & $(\mathrm{N})$ & 302 & 79 & 84 & 30 & 30 & 41 \\
\hline & $A$ & 0.194 & 0.222 & 0.226 & 0.150 & 0.267 & 0.146 \\
\hline & $B$ & 0.465 & 0.500 & 0.387 & 0.517 & 0.417 & 0.524 \\
\hline & $C$ & 0.333 & 0.259 & 0.375 & 0.333 & 0.317 & 0.329 \\
\hline & $D$ & 0.008 & 0.019 & 0.012 & 0.000 & 0.000 & 0.000 \\
\hline \multicolumn{8}{|l|}{$A d h_{l}$} \\
\hline & $(\mathrm{N})$ & 292 & 75 & 83 & 29 & 30 & 39 \\
\hline & $A$ & 0.022 & 0.007 & 0.024 & 0.000 & 0.033 & 0.038 \\
\hline & $B$ & 0.875 & 0.860 & 0.916 & 0.948 & 0.850 & 0.910 \\
\hline & $C$ & 0.099 & 0.133 & 0.060 & 0.052 & 0.100 & 0.038 \\
\hline & $D$ & 0.003 & 0.000 & 0.000 & 0.000 & 0.000 & 0.013 \\
\hline \multicolumn{8}{|l|}{$\mathrm{Pgi}_{2}$} \\
\hline & $(\mathrm{N})$ & 179 & 43 & 52 & 16 & 23 & 26 \\
\hline & $A$ & 0.011 & 0.023 & 0.000 & 0.000 & 0.000 & 0.038 \\
\hline & $B$ & 0.461 & 0.535 & 0.471 & 0.469 & 0.543 & 0.269 \\
\hline & $C$ & 0.067 & 0.093 & 0.106 & 0.031 & 0.022 & 0.019 \\
\hline & $D$ & 0.453 & 0.337 & 0.423 & 0.500 & 0.413 & 0.673 \\
\hline & $E$ & 0.008 & 0.012 & 0.000 & 0.000 & 0.022 & 0.000 \\
\hline
\end{tabular}

$(\mathrm{N})$ is the sample size for each locus.

Table $2 F_{\text {IS }}$ values for each subpopulation, using weighted averages to combine values across alleles at each locus. Significant departures from Hardy-Weinberg equilibrium were tested using heterogeneity chi-square analyses

\begin{tabular}{|c|c|c|c|c|c|c|}
\hline \multirow[b]{2}{*}{ Locus } & \multicolumn{5}{|c|}{ Subpopulation } & \multirow{2}{*}{$\begin{array}{l}\text { Weighted } \\
\text { mean }\end{array}$} \\
\hline & 1 & 2 & 3 & 4 & 5 & \\
\hline $\mathrm{Pgm}_{I}$ & -0.099 & -0.013 & -0.001 & -0.120 & -0.106 & $-0.068^{* *}$ \\
\hline$A d h_{1}$ & 0.395 & $0.694^{* *}$ & 0.648 & 0.127 & 0.391 & $0.322^{* * * *}$ \\
\hline $\mathrm{Pgi}_{2}$ & 0.055 & 0.051 & 0.055 & 0.184 & $0.430^{*}$ & 0.145 \\
\hline
\end{tabular}

versely, $P g m_{l}$ gave a non-significant negative value, indicating a slight excess of heterozygotes for the population. Where allelic frequencies show no differences among subpopulations (i.e. $\left.F_{\mathrm{ST}}=0\right), F_{\mathrm{IT}}$ and $F_{\mathrm{IS}}$ are usually considered equivalent (Eanes \& Koehn, 1978). The results obtained here for $F_{\text {IT }}$ were similar to, although slightly higher than, the $F_{\text {IS }}$ values obtained (Table 4). This indicates that although there was a small amount of differentiation between subpopulations, a larger proportion of the total fixation index $\left(F_{\mathrm{IT}}\right)$ appeared to be derived from values of $F_{\text {IS }}$.
The Wahlund effect arises when groups (or individuals) from different genetic sources are pooled or mixed. This mixing of individuals will thereby create departures from Hardy-Weinberg equilibrium, in the form of reductions in heterozygosity. However, in this population, geographic variation in allelic frequencies could not adequately explain the deficits found, and thus it appears that structuring contributes little overall to the deficits observed. Estimates of the proportion of heterozygote deficiencies that may have arisen through geographic variation in allele frequencies 
Table 3 Variation of allele frequencies in $B$. spinulosa among five subpopulations for three enzyme loci

\begin{tabular}{|c|c|c|c|c|}
\hline Locus & $p$ & $\sigma_{c}^{2}$ & $F_{\mathrm{ST}}$ & $P$ \\
\hline$P g m_{l}$ & & & & $<0.25$ \\
\hline$A$ & 0.202 & 0.00269 & 0.0167 & \\
\hline$B$ & 0.469 & 0.00353 & 0.0142 & \\
\hline$C$ & 0.323 & 0.00159 & 0.0073 & \\
\hline$D$ & 0.006 & 0.00007 & 0.0112 & \\
\hline$A d h_{l}$ & & & & $<0.10$ \\
\hline$A$ & 0.02 & 0.00023 & 0.0118 & \\
\hline$B$ & 0.897 & 0.00182 & 0.0197 & \\
\hline$C$ & 0.077 & 0.00186 & 0.0262 & \\
\hline$D$ & 0.006 & 0.00006 & 0.0097 & \\
\hline $\mathrm{Pgi}_{2}$ & & & & $<0.025$ \\
\hline$A$ & 0.012 & 0.00027 & 0.0228 & \\
\hline$B$ & 0.457 & 0.01122 & 0.0452 & \\
\hline$C$ & 0.054 & 0.00184 & 0.0360 & \\
\hline$D$ & 0.469 & 0.01522 & 0.0611 & \\
\hline$E$ & 0.007 & 0.00097 & 0.1396 & \\
\hline
\end{tabular}

$p=$ average allele frequency, $\sigma_{c}^{2}=$ variance corrected for binomial sampling effects, $P$ is the probability from G-tests.

Table 4 Summary of F-statistics for all loci over the five subpopulations

\begin{tabular}{lrlrrl}
\hline Locus & \multicolumn{1}{c}{$F_{\mathrm{IS}}$} & \multicolumn{1}{l}{$F_{\mathrm{ST}}$} & \multicolumn{1}{c}{$F_{\mathrm{IT}}$} & \multicolumn{1}{l}{$\chi$} & $P$ \\
\hline Pgm & -0.068 & 0.011 & -0.057 & 2.57 & \multicolumn{1}{l}{ ns } \\
Adh $_{1}$ & 0.322 & 0.015 & 0.332 & 84.65 & $<0.001$ \\
$\mathrm{Pgi}_{2}$ & 0.145 & 0.043 & 0.182 & 21.20 & $<0.025$ \\
Mean & 0.071 & 0.025 & 0.094 & & \\
\hline
\end{tabular}

Statistical significance of $F_{\text {IT }}$ was calculated from $\chi^{2}=F_{\mathrm{IT}} 2 \mathrm{~N}(n-1)$, where $\mathrm{N}$ is the sample size for each locus and $n$ is the number of alleles, with $n(n-1) / 2 \mathrm{~d}$.f. (Ellstrand \& Levin, 1980).

revealed that only 12.5 per cent could be attributed to the Wahlund effect (Table 5). Not surprisingly, $\mathrm{Pgi}_{2}$ gave by far the greatest contribution, accounting for 42.85 per cent of this value. The negative value obtained for $P g m_{1}$ was derived from the slight excess of heterozygotes for this locus.

Analysis of Nei's (1978) genetic distance and genetic identity values indicated that there was relatively little differentiation among the designated subdivisions in this population. This is illustrated by the low genetic distance and high genetic identity values given in Table 6. However, those areas with greatest geographic distance between them did give the highest genetic distance values (Fig. 2), and subpopulation number 5,
Table 5 Proportions of heterozygote deficits that could be attributed to variances of allelic frequencies among subpopulations (the Wahlund effect)

\begin{tabular}{lc}
\hline Locus & $\Sigma \sigma^{2} /\left(H_{\mathrm{e}}-H_{\mathrm{o}}\right)$ \\
\hline$P g m_{1}$ & -0.1956 \\
$A d h_{l}$ & 0.0518 \\
$P g i_{2}$ & 0.4285 \\
Mean & 0.0949 \\
S.E. & 0.1814 \\
\hline
\end{tabular}

$\Sigma \sigma^{2}$ denotes the corrected variance, summed for each locus, $H_{\mathrm{e}}$ the expected proportion of heterozygotes and $H_{\mathrm{o}}$ the observed proportion of heterozygotes at each locus.

Table 6 Nei's (1978) unbiased genetic distance (above diagonal) and identities (below diagonal) among the five designated subpopulations. Mean distance between any one subpopulation and all others is given below

\begin{tabular}{llllll}
\hline Subpopulation & 1 & 2 & 3 & 4 & 5 \\
\hline 1 & - & 0.008 & 0.004 & 0.000 & 0.055 \\
2 & 0.992 & - & 0.000 & 0.000 & 0.033 \\
3 & 0.996 & 1.000 & - & 0.000 & 0.008 \\
4 & 1.000 & 1.000 & 1.000 & - & 0.039 \\
5 & 0.947 & 0.968 & 0.992 & 0.962 & - \\
Mean distance & 0.017 & 0.010 & 0.003 & 0.009 & 0.038 \\
\hline
\end{tabular}

which was the furthest away from the others, exhibited a higher mean distance value (Table 6), indicating some differences in this part of the population.

\section{Discussion}

This population of Banksia spinulosa is highly outcrossed (Carthew et al., 1988), yet there was evidence of some genetic differentiation among the designated subpopulations, and the population as a whole apparently deviates somewhat from a single panmictic unit. Significant deficits of heterozygotes were observed at two of the three loci used. The general prediction for predominantly outcrossing species is that populations should retain a high degree of genetic variability, and achieve extensive mixing of genes (Hamrick et al., 1979). However, Brown (1979) has noted an apparent 'paradox' between inbreeders and outcrossing species, with outcrossing species often exhibiting heterozygote deficiencies. Although a deficiency of heterozygotes has commonly been cited as evidence for inbreeding (see Linhart et al., 1981) there are many other reasons for such patterns, including differential fertility among genotypes (see Muller-Stark et al., 


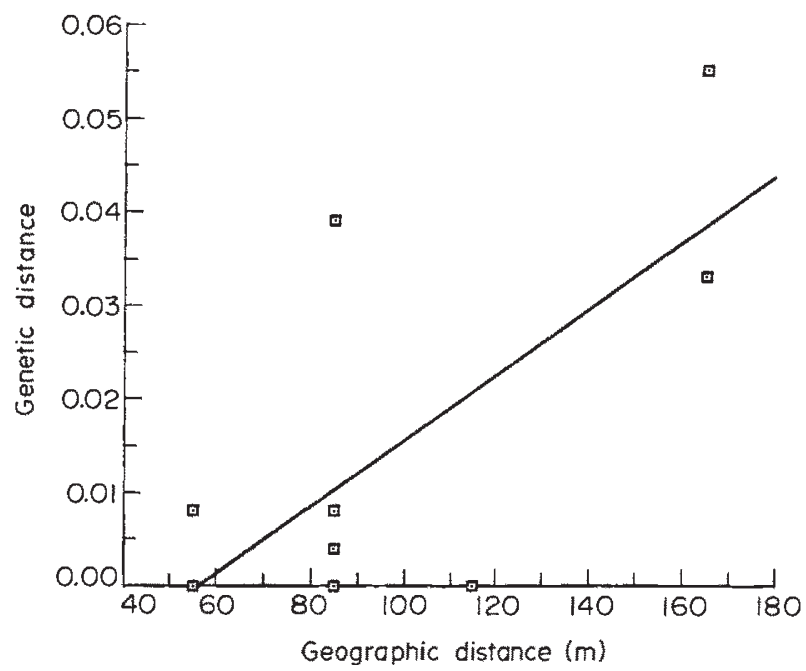

Fig. 2 Graphical relationship between the genetic distance (Nei, 1978) and geographic distance for five subpopulations of $B$. spinulosa. Geographic distances are taken from the midpoint of each subpopulation.

1983), and the Wahlund effect (whereby individuals from more than one breeding unit are sampled as if they were a single population). If deviations were primarily a consequence of the mating system, such an influence would be expected to be consistent across loci (Soltis \& Soltis, 1988), which is clearly not the case here. For $A d h_{1}$ it is likely that the presence of a null allele contributed to the observed heterozygote deficit. At this locus, there was no evidence of heterogeneity of gene frequencies, and thus little likelihood of a Wahlund effect. However, further analysis of the null allele at this locus is required to ascertain its frequency in the population. $P g i_{2}$ also showed a marked deficit of heterozygotes, with some heterogeneity of allelic frequencies and highly significant $F_{\mathrm{ST}}$ values. For this locus, examination of the percentage of heterozygote deficits which could be attributed to the Wahlund effect revealed that nearly 50 per cent of them could be accounted for by variations in allelic frequencies among the subpopulations. As pointed out by Wendel \& Parks (1985) and Slatkin (1985), selection and/or mutation will give rise to differences in the heterogeneity of genes at different loci, and it is not necessary for loci to behave similarly to invoke a Wahlund effect. Finally, the patterns observed at this locus may have arisen through selection against heterozygotes at some stage of the life cycle (Allard et al., 1977). Conclusive evidence of this effect requires more detailed analysis of both parental and progeny genotypes, preferably from controlled breeding experiments.

As there have been no other published studies on spatial genetic variability in species of Proteaceae, it is not possible to determine whether the patterns observed for a single population of $B$. spinulosa are typical for other populations or species in the family. However, these results can be compared with other long-lived perennial plants which are typically outcrossing. In a review of microgeographical differentiation among species of differing life histories, Loveless \& Hamrick (1984) concluded that the prime determinant of genetic structure is the breeding system. However, studies on population substructure in plant populations are typified by variability in results. Population genetic structure has been shown to vary among closely related species (e.g. van Dijk et al., 1988), between those with similar breeding systems, and even among different populations of the same species (e.g. Soltis \& Soltis, 1988). Substructuring in populations of outcrossing species is particularly common in annuals and conifers, and is often attributed to restricted, or patchy gene flow. It should be noted, however, that even though many populations of outcrossing species show evidence of structuring and differentiation, it is to a much lesser degree than for selfing species (see Loveless \& Hamrick, 1984). This population of $B$. spinulosa appears to follow that trend in that although deviations from panmixia are evident from the F-statistics presented here, these deviations are small in comparison to other species studied.

Gene flow plays a major role in shaping the spatial distribution of genes in a population. In plant populations, gene flow is mediated through both pollen and seed dispersal, and a prevailing view is that gene flow is quite restricted (Levin, 1981; Hamrick, 1982). Dispersal of pollen and/or seed usually follows a leptokurtotic distribution, with most dispersal occurring within a few metres of the parent plant (e.g. Bos et al., 1986). Thus, individuals generally mate with neighbouring ones, generating small neighbourhood sizes (e.g. Cahalan \& Gliddon, 1985). One commonly used measure of gene flow is given by the relationship $F_{\mathrm{ST}}=1 /(4 N m+1)$ (Wright, 1951, 1965). $\mathrm{Nm}$ in this case is the amount of intrapopulation gene flow (i.e. the product of effective population size and the rate of migration). This measure is thought to be a good approximation for gene flow where $m$ is small, the main assumption being that alleles are neutral (Slatkin, 1985; see also Slatkin \& Barton (1989) for an evaluation of methods). Most estimates of gene flow have used species with discrete generations, and very few studies have addressed the assumptions of this measure. Nevertheless, it is possible to gain a rough estimate for species which have overlapping generations (see for example, Larson et al., 1984; Waples, 1987), and it appears that at least for estimates of effective population numbers, overlapping generations make little difference to the calculation of 
$N_{\mathrm{e}}$ (Hill, 1972; Crow \& Denniston, 1988). From the measure of $\mathrm{Nm}$, an approximation for neighbourhood size $N_{b}=2 \pi N m$ (where $N_{b}$ is the number of individuals which can interbreed) can also be obtained (Slatkin \& Barton, 1989). Values greater than one imply relatively extensive gene flow, and a limited capacity for genetic differentiation within a population. When applied to the population of $B$. spinulosa, a value of approximately 9.75 for $\mathrm{Nm}$, and a neighbourhood size of 61 individuals is obtained. This indicates that the movement of genes occurs over a fairly wide area in this population, despite the finding of some differentiation in the population.

Most species for which estimates of gene flow are available are wind- or insect-pollinated. $B$. spinulosa is pollinated primarily by birds and small mammals, which are relatively mobile (Carthew, 1992). Observations on pollinator behaviour indicate that both short and long distance movements by pollinators are quite common, and that pollen dispersal regimes are likely to show considerable variability (Carthew, 1991). Furthermore, although seed dispersal has not been examined in this study, results from two other Banksia species (Abbott, 1985; R. Whelan personal communication) indicate that this component of gene flow is likely to be quite limited. Thus, in accord with many other plant species, gene flow in $B$. spinulosa might be expected to be more restricted than it appears. However, patterns of pollen receipt in this population do not reflect actual matings between individuals. Levels of outcrossing are extremely high (Carthew et al., 1988) and although the species is not completely selfincompatible, breeding experiments indicate that outcrossed seed is preferentially selected (Carthew, 1991). Moreover, it should be remembered that actual gene flow is determined by reproductively mature plants (Goldenberg, 1987). For this population of B. spinulos $a$, it is impossible to know what other selective processes may have occurred prior to and during the establishment of the existing population, as these plants are long-lived shrubs, and are able to resprout after fire.

\section{Acknowledgements}

D. Ayre and R. Whelan are thanked for comments on an earlier draft of the manuscript. This is contribution number 097 of the EGC at the University of Wollongong.

\section{References}

ABвOTT, I. 1985. Reproductive ecology of Banksia grandis (Proteaceae). New Phytol., 99, 129-148.
ABBOTT, R. J. AND GOMES, M. F. 1989. Population genetic structure and outcrossing rate of Arabidopsis thaliana (L.) Heynh. Heredity, 62, 411-418.

ALlARD, R. W., KAHLER, A. L. AND CLEGG, M. T. 1977. Estimation of mating cycle components of selection in plants. In: Christiansen, F. B. and Fechenel, T. M. (eds) Measuring Selection in Natural Populations. Springer Verlag, Berlin, pp. $1-19$.

BOS, M., HARMENS, H. AND VRIELing, K. 1986. Gene flow in Plantago. $I$. Gene flow and neighbourhood size in $P$. lanceolata. Heredity, 56, 43-54.

BROWN, A. H. D. 1979. Enzyme polymorphism in plant populations. Theor. Pop. Biol., 15, 1-42.

CAHALAN, C. M. AND GLIDDON, C. 1985. Genetic neighbourhood sizes in Primula vulgaris. Heredity, 54, 65-70.

CARTHEW, S. M. 1991. The pollination biology and breeding system of Banksia spinulosa. Ph.D Thesis, University of Wollongong, Australia.

CARTHEW, S. M. 1993. An assessment of pollinator vistation to Banksia spinulosa. Aust. J. Ecol., 18, in press.

CARTHEW, S. M., AYRE, D. J. AND WHELAN, R. J. 1988. High levels of outcrossing in populations of Banksia spinulosa R. Br. and Banksia paludosa Smith. Aust. J. Bot., 36, 217-223.

CROW, J. F. AND DENNISTON, C. 1988. Inbreeding and variance effective population numbers. Evolution, 42, 482-495.

EANES, W. F. AND KOEHN, R. K. 1978. An analysis of genetic structure in the Monarch butterfly, Danus plexippus L. Evolution, 32, 784-797.

ELLSTRAND, N. C. AND LEVIN, D. A. 1980. Recombination system and population structure in Oenothera. Evolution, 34, 923-933.

ENNOS, R. A. 1985. The mating system and genetic structure in a perennial grass, Cynosurus cristatus L. Heredity, 55, 121-126.

FURNIER, G. R., KNOWLES, P., CLYDE, M. A. AND DANCIK, B. P. 1987. Effects of avian seed dispersal on the genetic structure of whitebark pine populations. Evolution, 4, 607-612.

GOLDENBERG, E. M. 1987. Estimation of gene flow and genetic neighbourhood size by indirect methods in a selfing annual, Triticum dicoccoides. Evolution, 41, 1326-1334.

HAMRICK, J. L. 1982. Plant population genetics and evolution. Am. J. Bot., 69, 1685-1693.

HAMRICK, J. L., LINHART, Y. B. AND MITTON, J. B. 1979. Relationships between life history characteristics and electrophoretically detectable genetic variation in plants. Ann. Rev. Ecol. Syst., 10, 173-200.

HEDRICK, P. W. 1985. Inbreeding and selection in natural populations. In: Gregorius, H-R. (ed) Lecture Notes in Biomathematics. 60. Population Genetics and Forestry. Springer Verlag, Berlin, pp. 71-91.

HILL, W. G. 1972. Effective size of populations with overlapping generations. Theor. Pop. Biol., 3, 278-289.

JOHNSON, M. S. AND BLACK, R. 1984. The Wahlund effect and the geographical scale of variation in the intertidal limpet Siphonaria sp. Mar. Biol., 79, 295-302.

LARSON, A., WAKE, D. B. AND YANEV, K. P. 1984. Measuring gene flow among populations having high levels of genetic fragmentation Genetics, 106, 292-308. 
LEVIN, D. A. 1981. Dispersal versus gene flow in plants. Ann. Miss. Bot. Gard., 68, 233-253.

LINHART, Y. B., MITTON, J. B., STURGEON, K. B. AND DAVIES, M. L 1981. Genetic variation in space and time in a population of ponderosa pine. Heredity, 46, 407-426.

LOVELESS, M. D. AND HAMRICK, J. L. 1984. Ecological determinants of genetic structure in plant populations. Ann. Rev. Ecol. Syst., 15, 65-95.

MITTON, J. B., sTURGEON, K. B. AND DAVIS, M. L. 1980. Genetic differentiation in ponderosa pine along a steep elevational transect. Silvae Genet., 29, 3-4.

MULLER-STARK, G., ZIEHE, M. AND HATTEMER, H. H. 1983. Reproductive systems in conifer seed orchards. 2. Reproductive selection monitored at an LAP gene locus in Pinus sylverstri L. Theor. Appl. Genet., 65, 309-316.

NEl, M. 1978. Estimation of average heterozygosity and genetic distance from a small number of individuals. Genetics, 89, 583-590.

SILANDER, J. A. 1984. The genetic basis of the ecological amplitude of Spartina patens. III. Allozyme variation. Bot. Gaz., 145, 569-577.

SLATKIN, M. 1985. Gene flow in natural populations. Ann. Rev. Ecol. Syst., 16, 393-430.

SLATKIN, M. AND BARTON, N. H. 1989. A comparison of three indirect methods for estimating average levels of gene flow. Evolution, 43, 1349-1368.
SMYTH, C. A. AND HAMRICK, J. L. 1987. Realized gene flow via pollen in artificial populations of musk thistle Carduus nutans L. Evolution, 41, 613-619.

SOLTIS, P. S. AND SOLTIS, D. E. 1988. Genetic variation and population structure in the fern Blechnum spicant (Blechnaceae) from Western North America. Am. J. Bot., 75, $37-44$.

SWOFFORD, D. L. AND SELANDER, R. B. 1981. BJOSYS-1. University of Illinois, Urbana, IL.

VAN DIJK, H., WOLFF, K. AND DE VRIES, A. 1988. Genetic variability in Plantago species in relation to their ecology. 3. Genetic structure of populations of $P$. major, $P$. lanceolata and $P$. coronopus. Theor. Appl. Genet., 75, 518-528.

WAPLES, R. S. 1987. A multispecies approach to the analysis of gene flow in marine shore fishes. Evolution, 41, 385-400.

WENDEL, J. F. AND PARKS, C. R. 1985. Genetic diversity and population structure in Camellia japonica $\mathrm{L}$. (Theaceae). Am. J. Bot., 72, 52-65.

WRIGHT, S. 1951. The genetical structure of populations. Ann. Eugen, 15, 323-354.

WRIGHT, S. 1965. The interpretation of population structure by F-statistics with special regard to systems of mating. Evolution, 19, 395-420.

WRIGHT, s. 1978. Evolution and Genetics of Populations, Vol. 4; Variability Within and Among Populations. University of Chicago Press, Chicago. 